\title{
Color Etching of Mg-Al Alloys
}
A. Maltais, ${ }^{*}$ M. Fiset* and D. Dubé*
* Department of Mining, Metallurgical and Materials Engineering, Université Laval, Québec, Qc, G1K 7P4, Canada

The metallographic preparation of $\mathrm{Mg}-\mathrm{Al}$ alloys for grain size evaluation is usually performed in two steps: 1) a solid solution heat treatment $\left(380-420^{\circ} \mathrm{C}\right.$ for $\left.0.5-24 \mathrm{~h}\right)$ followed by rapid cooling induces precipitation of secondary phases at grain boundaries and; 2) a chemical etch selectively stains the matrix or aluminum-rich phases, which in turn accentuates grain boundaries (See Fig. 1). This heat-treating step is time consuming, alters the dendritic structure of $\mathrm{Mg}$-Al alloys and promotes grain growth, leading to wrong grain size estimates [1]. This paper describes a simplified procedure for accurate evaluation of as-cast grain size and texture in $\mathrm{Mg}$-Al alloys. This technique has been applied to study the grain refining effect of mechanical vibrations in $\mathrm{Mg}$-Al alloys [2].

The proposed metallographic procedure consists of etching mechanically polished samples in a solution containing $1 \mathrm{ml}$ glacial acetic acid, $50 \mathrm{ml}$ distilled water and $150 \mathrm{ml}$ anhydrous ethyl alcohol for approximately 60-240s [3]. The specimen is then rinsed in anhydrous ethyl alcohol and dried with a blast of air. Examination of the grain structure is carried out macroscopically under diffuse light and microscopically under crossed polarized light (See Fig. 2). The use of a retardation plate is recommended to facilitate differentiation during grain size evaluation.

The phenomena responsible for this remarkable contrast between grains were investigated. Scanning electron micrographs of etched samples revealed that a crackled film is formed at the surface of etched specimens; the orientation of cracks being related to the crystalline orientation of underlying grains [3]. Shrinking stresses, which occur upon drying, crackle the film. The parallelism of cracks could be explained by the presence of a specific cleavage plane in the deposited layer. Repeated experiments in our laboratory indicate that the crackling pattern is influenced by solute concentration in the matrix, drying conditions and etching time [3-4].

The optical anisotropy of a mechanically polished grain of AZ91D magnesium alloy was determined using an ellipsometer prior and after color etching. It was found that reflection and phase shift of as-polished grain does not depend on its orientation. However, after etching, the reflection of light at oblique incidence is strongly anisotropic being maximal as light travels parallel to the cracks and minimal as it travels perpendicular to them. The phase shift upon reflection at near normal incidence is only weakly anisotropic after etching.

From theses experiments, it is concluded that the contrast between grains under diffuse light is attributed to the absorption of incoming light traveling perpendicularly across the cracks. The contrast between grains under crossed polarized light arises from the periodic structure of the surface, which exhibits form birefringence. Accordingly, if the etched sample is wet with a liquid such as ethyl alcohol, the refractive index of which is very close to the index of the film, the polarization phenomenon completely disappears. Discrepancies between the anisotropy observed with the polarizing microscope and measured with the ellipsometer imply that birefringence does not occur throughout the film, but only near the cracks. 


\section{References}

[1] J. Thomson, et al., 108th Metalcasting Congress. Rosemont, IL, June 12-15 (2004).

[2] A. Maltais et al., Mater. Sci. For. 426-432 (2003) 527.

[3] A. Maltais et al., Mater. Charact. 52 (2004) 103.

[4] A. Maltais et al., Mater. Charact. To be published.

[5] This research was supported by grants from NSERC and FCAR (CERPIC Center). The help of M. Larouche, A. Ferland and G. Paul-Hus was greatly appreciated.
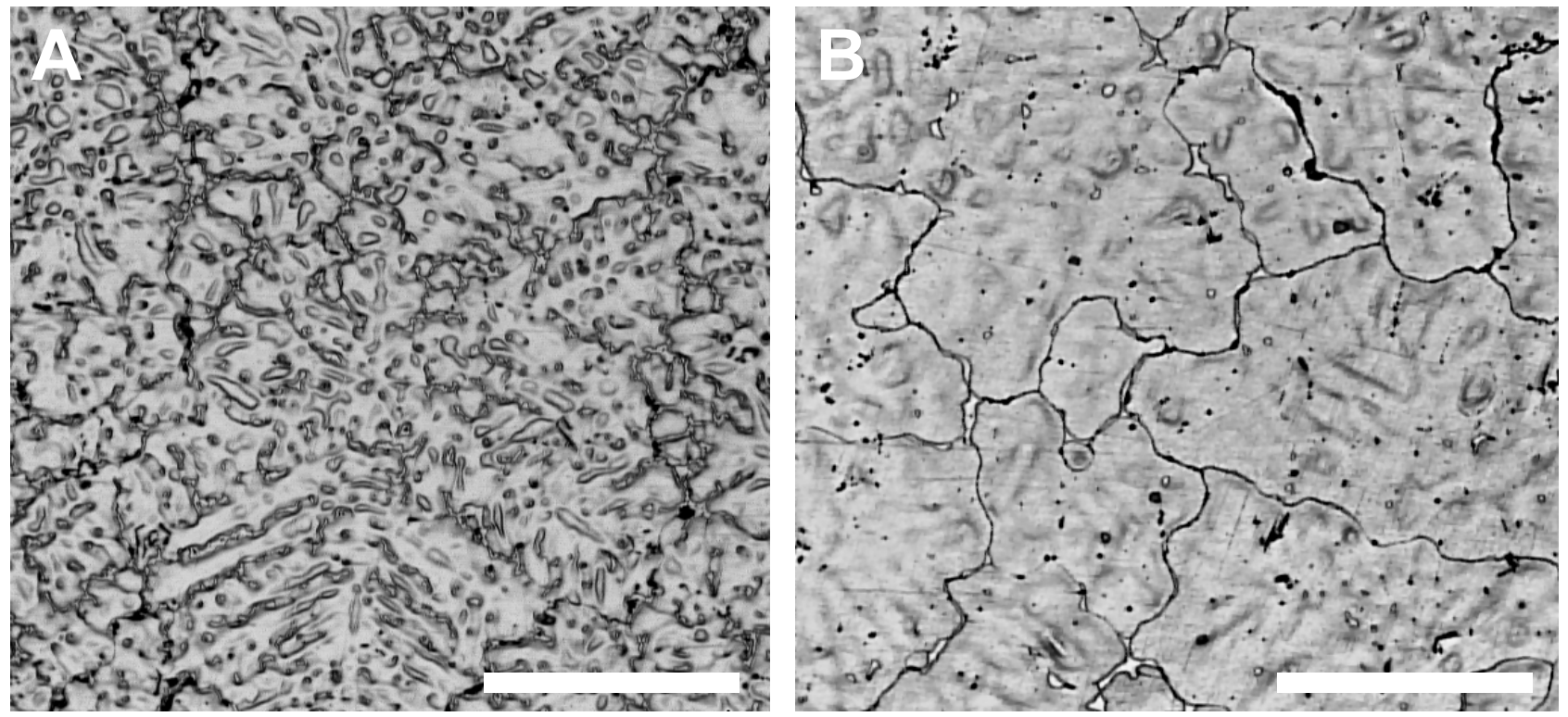

Fig. 1. Brightfield micrographs of gravity-cast AZ91D alloy etched 30s in $1 \mathrm{ml}$ nitric acid, 20ml acetic acid, $24 \mathrm{ml}$ water and $75 \mathrm{ml}$ glycol. A. As-cast. B. Heat treated $412^{\circ} \mathrm{C} / 2 \mathrm{~h}$. Scale bar $=500 \mu \mathrm{m}$.
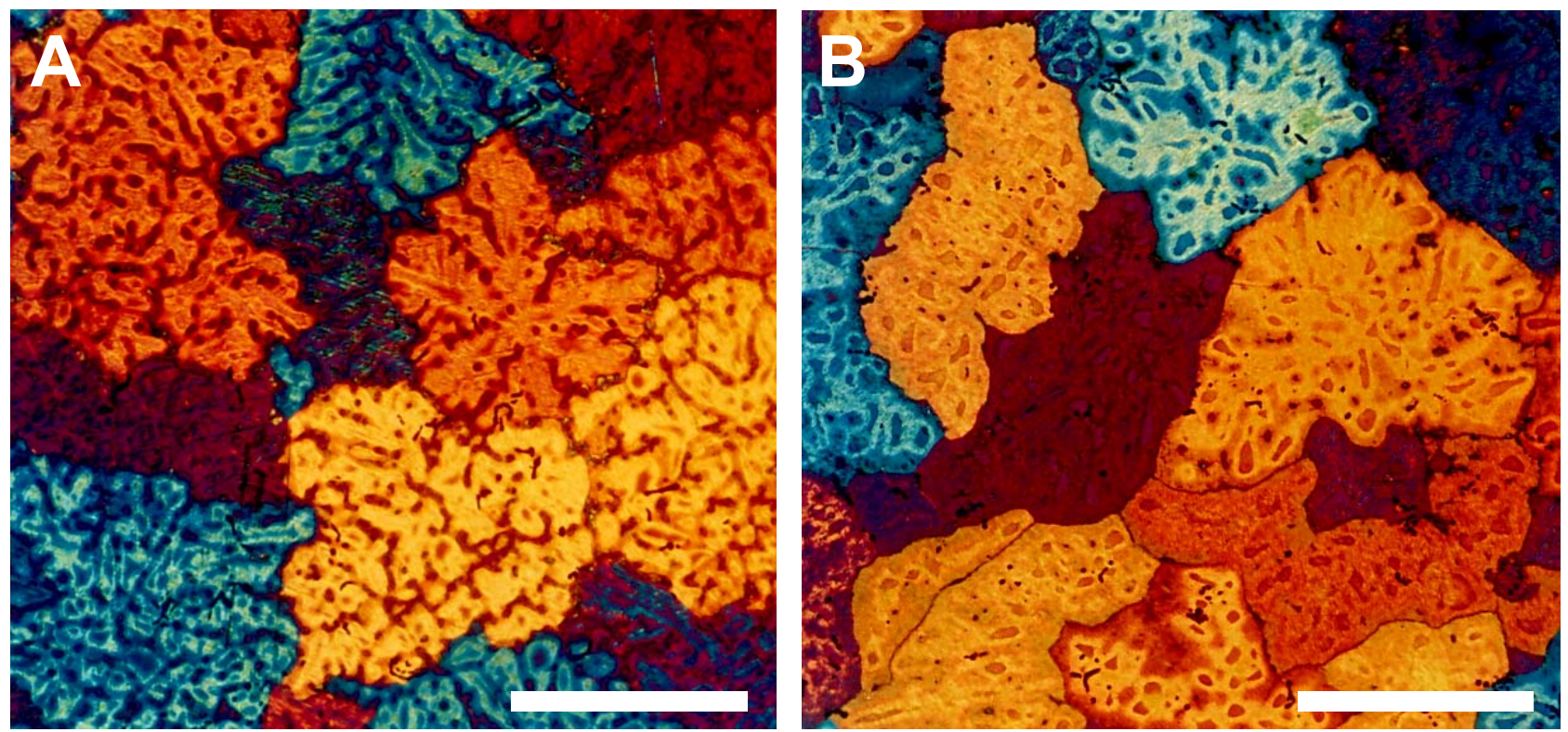

Fig. 2. Polarized micrographs of gravity cast AZ91D etched $180 \mathrm{~s}$ in $1 \mathrm{ml}$ acetic acid, 50ml water and $150 \mathrm{ml}$ ethyl alcohol. A. As-cast. B. Heat treated $412^{\circ} \mathrm{C} / 2 \mathrm{~h}$. Scale bar $=400 \mu \mathrm{m}$. 